\title{
EDITORIAL
}

\section{Handheld optical coherence tomography removes barriers to imaging the eyes of young children}

(c) The Author(s), under exclusive licence to The Royal College of Ophthalmologists 2021

Eye (2022) 36:907-908; https://doi.org/10.1038/s41433-021-01884-5

Optical coherence tomography (OCT) has revolutionised the clinical practice of ophthalmology. Its use has become widespread across most major branches of ophthalmology, including medical retina, surgical retina, glaucoma, neuro-ophthalmology, uveitis, cornea, anterior segment and refractive surgery, primary care ophthalmology and ocular oncology. However, conventional table-mounted OCT devices are not designed for infants and young children, who have previously been deprived of this technology and its many clinical benefits. Furthermore, many research studies using table-mounted OCT devices have previously excluded infants and young children.

Nicholson et al. [1] successfully used handheld spectral-domain OCT in a cohort of children with Down syndrome aged 4-11 years old. They demonstrated good feasibility of handheld OCT with successful scans in 12 out of 14 children (86\%). Interestingly, at the fovea, they found that the ganglion cell layer and inner nuclear layer were thickened relative to the control group. At the parafovea, they found thickening of the retina attributable to numerous layers in both the inner and outer retina. They also reported a high incidence $(67 \%)$ of foveal hypoplasia-higher than previously reported. All cases of foveal hypoplasia were grade 1 [2]; this is associated with a better visual prognosis than higher grades of foveal hypoplasia [3]. If visual acuity is poorer than expected for mild foveal hypoplasia, clinical suspicion should be raised for other pathology limiting the visual acuity. Other ocular conditions, such as infantile glaucoma, corneal ectasia or retinal pathology, can also be diagnosed and managed in this patient group with the advantages of handheld spectraldomain OCT.

Handheld OCT has been used to study the normal development of the fovea [4] from birth to adulthood, and the optic nerve head [5] from birth to adolescence. Handheld OCT has also been used to study a wide range of conditions affecting the paediatric population, providing useful diagnostic information, permitting serial monitoring, guiding clinical management and, in many cases, overcoming unique challenges in certain patient groups. Handheld OCT can be used in premature infants during the first days of life to evaluate retinopathy of prematurity (in dilated [6] and undilated [7] pupils), hypoxic-ischaemic encephalopathy [7] and obstructive hydrocephalus [7], without sedation. It is feasible and reliable in children with constant involuntary eye movements characteristic of nystagmus [3, 8, 9] and has been used to study the following associated conditions: foveal hypoplasia [3, 9], albinism [3, 9], achromatopsia [3], PAX6 mutations [9] and SLC38A8 mutations [10]. It has also been used in idiopathic infantile nystagmus $[3,9]$. It has demonstrated good feasibility and repeatability in infants and young children with craniosynostosis [11], including its syndromic forms often associated with developmental delay. It has been used in children with primary congenital glaucoma [12, 13], anterior segment dysgenesis [14], optic nerve hypoplasia [15], retinal detachment [16], retinoschisis [16], retinoblastoma [17], optic pathway gliomas [18] and other ocular conditions. It has also been used in children with other conditions affecting the skull and brain, including microcephaly [19], cerebral malaria [20] and in craniopagus twins conjoined at the skull [21].

Performing handheld OCT in children is both an art and a science. Specialised training in handheld OCT image acquisition is required. Under the right circumstances, children of all ages can be imaged in the eye clinic without sedation. Engaging the parents/carers can be hugely beneficial-once they understand the aim and purpose of the examination, they often become invested in achieving good imaging by keeping the child calm and offering their favourite toys/cartoons as visual fixation devices, as the handheld OCT does not feature an in-built fixation target. Undilated handheld OCT is feasible in most cases. Sometimes, dilating the child's pupils can be counter-productive, as it may distress them and make handheld OCT imaging more challenging. A short acquisition time can be used, e.g., $1.9 \mathrm{~s}$, to facilitate successful image acquisition with minimal disruption of quality. The scan window can be adjusted to image both the fovea and optic nerve head in one scan, e.g. $12 \mathrm{~mm} \times 8 \mathrm{~mm}$. It can be beneficial to have one person aiming the handheld OCT probe and a second person using the computer to acquire the scan. The continuous real-time imaging 'free run' mode can be used, as this refreshes every $1.68 \mathrm{~s}$, providing enough time to stop the acquisition and save the last acquired image-this is particularly useful in pre-verbal infants where cooperation and fixation can be more challenging. If a second person is not available, then the foot-pedal can be used to acquire images.

In babies, it can be useful to allow enough clinic time for the parents/carers to settle the baby prior to the examination, with particular emphasis on feeding. It is possible and sometimes easier to perform handheld OCT in a baby whilst they are napping by gently opening the lids. In an awake baby, provided they are not distressed, handheld OCT can still be performed without dilation. In toddlers, it can be very useful to have the parent/carer or a second clinician holding a visual fixation device, such as a toy or cartoon on a tablet/smartphone, moving this as instructed by the clinician operating the handheld OCT such that they visualise the structures of interest. As soon as the child is old enough to understand the purpose of the handheld OCT examination, it can be beneficial to explain the purpose of the examination so that they become invested in achieving good imaging too. Furthermore, in research studies, it can be beneficial for all parties to actively involve and engage children, parents and carers in all stages of the study [22].

Handheld OCT is a relatively young science with unique challenges, such as the need for specialist training in image acquisition and analysis, lack of in-built fixation target and currently there is no automated image segmentation/analysis programme. However, with specialised training, infants and young children of all ages can benefit from handheld OCT imaging. 
Sohaib R. Rufai ${ }^{1,2}{ }^{\text {凶 }}$

${ }^{1}$ University of Leicester Ulverscroft Eye Unit, Leicester, UK. ${ }^{2}$ Clinical and Academic Department of Ophthalmology, Great Ormond Street Hospital for Children and UCL GOS Institute of Child Health, London, UK. ${ }^{凶}$ email: Sohaib.Rufai@nhs.net

\section{REFERENCES}

1. Nicholson R, Osborne D, Fairhead L, Beed L, Hill CM, Lee H. Segmentation of the foveal and parafoveal retinal architecture using handheld spectral-domain optical coherence tomography in children with Down syndrome. Eye. 2021 (In Press).

2. Thomas MG, Kumar A, Mohammad S, Proudlock FA, Engle EC, Andrews C, et al. Structural grading of foveal hypoplasia using spectral-domain optical coherence tomography a predictor of visual acuity? Ophthalmology. 2011;118:1653-60. https:// doi.org/10.1016/j.ophtha.2011.01.028. Erratum in: Ophthalmology. 2011;118:1910.

3. Rufai SR, Thomas MG, Purohit R, Bunce $C$, Lee $H$, Proudlock FA, et al. Can structural grading of foveal hypoplasia predict future vision in infantile nystagmus?: a longitudinal study. Ophthalmology. 2020;127:492-500. https://doi.org/10.1016/j. ophtha.2019.10.037.

4. Lee $H$, Purohit R, Patel A, Papageorgiou E, Sheth V, Maconachie G, et al. In vivo foveal development using optical coherence tomography. Invest Ophthalmol Vis Sci. 2015;56:4537-45. https://doi.org/10.1167/iovs.15-16542.

5. Patel A, Purohit R, Lee H, Sheth V, Maconachie G, Papageorgiou E, et al. Optic nerve head development in healthy infants and children using handheld spectral-domain optical coherence tomography. Ophthalmology. 2016;123:2147-57. https://doi.org/ 10.1016/j.ophtha.2016.06.057.

6. Anwar S, Nath M, Patel A, Lee H, Brown S, Gottlob I, et al. Potential utility of foveal morphology in preterm infants measured using hand-held optical coherence tomography in retinopathy of prematurity screening. Retina. 2020;40:1592-602. https://doi. org/10.1097/IAE.0000000000002622.

7. Tran-Viet D, Wong BM, Mangalesh S, Maldonado R, Cotten CM, Toth CA. Handheld spectral domain optical coherence tomography imaging through the undilated pupil in infants born preterm or with hypoxic injury or hydrocephalus. Retina. 2018;38:1588-94. https://doi.org/10.1097/IAE.0000000000001735.

8. Lee $\mathrm{H}$, Proudlock F, Gottlob I. Is handheld optical coherence tomography reliable in infants and young children with and without nystagmus? Invest Ophthalmol Vis Sci. 2013;54:8152-9. https://doi.org/10.1167/iovs.13-13230.

9. Lee $H$, Sheth V, Bibi M, Maconachie G, Patel A, McLean RJ, et al. Potential of handheld optical coherence tomography to determine cause of infantile nystagmus in children by using foveal morphology. Ophthalmology. 2013;120:2714-24. https:// doi.org/10.1016/j.ophtha.2013.07.018.

10. Kuht HJ, Han J, Maconachie GDE, Park SE, Lee ST, McLean R, et al. SLC38A8 mutations result in arrested retinal development with loss of cone photoreceptor specialization. Hum Mol Genet. 2020;29:2989-3002. https://doi.org/10.1093/hmg/ ddaa166.

11. Rufai SR, Bowman R, Bunce C, Panteli V, McLean RJ, Teli S, et al. Feasibility and repeatability of handheld optical coherence tomography in children with craniosynostosis. Transl Vis Sci Technol. 2021;10:24

12. Pilat AV, Proudlock FA, Shah S, Sheth V, Purohit R, Abbot J, et al. Assessment of the anterior segment of patients with primary congenital glaucoma using handheld optical coherence tomography. Eye (Lond). 2019;33:1232-9. https://doi. org/10.1038/s41433-019-0369-3.

13. Shah SD, Haq A, Toufeeq S, Tu Z, Edawaji B, Abbott J, et al. Reliability and recommended settings for pediatric circumpapillary retinal nerve fiber layer imaging using hand-held optical coherence tomography. Transl Vis Sci Technol. 2020;9:43 https://doi.org/10.1167/tvst.9.7.43.

14. Pilat AV, Sheth V, Purohit R, Proudlock FA, Anwar S, Gottlob I. Hand-held optical coherence tomography imaging in children with anterior segment dysgenesis. Acta Ophthalmol. 2017:95:537-41. https://doi.org/10.1111/aos.13053.
15. Pilat A, Sibley D, McLean RJ, Proudlock FA, Gottlob I. High-resolution imaging of the optic nerve and retina in optic nerve hypoplasia. Ophthalmology. 2015;122:1330-9. https://doi.org/10.1016/j.ophtha.2015.03.020.

16. Chen X, Prakalapakorn SG, Freedman SF, Vajzovic L, Toth CA. Differentiating retinal detachment and retinoschisis using handheld optical coherence tomography in stage 4 retinopathy of prematurity. JAMA Ophthalmol. 2020;138:81-85. https://doi.org/10.1001/jamaophthalmol.2019.4796.

17. Soliman SE, VandenHoven C, MacKeen LD, Héon E, Gallie BL. Optical coherence tomography-guided decisions in retinoblastoma management. Ophthalmology. 2017;124:859-72. https://doi.org/10.1016/j.ophtha.2017.01.052.

18. Avery RA, Cnaan A, Schuman JS, Trimboli-Heidler C, Chen CL, Packer RJ, et al. Longitudinal change of circumpapillary retinal nerve fiber layer thickness in children with optic pathway gliomas. Am J Ophthalmol. 2015;160:944.e1. https:// doi.org/10.1016/j.ajo.2015.07.036.

19. Papageorgiou E, Pilat A, Proudlock F, Lee H, Purohit $R$, Sheth V, et al. Retinal and optic nerve changes in microcephaly: an optical coherence tomography study. Neurology. 2018:91:e571-e585. https://doi.org/10.1212/WNL.0000000000005950.

20. Tu Z, Gormley J, Sheth V, Seydel KB, Taylor T, Beare N, et al. Cerebral malaria: insight into pathology from optical coherence tomography. Sci Rep. 2021;11:15722 https://doi.org/10.1038/s41598-021-94495-9.

21. Rufai SR, Gore S, Handley SE, Marmoy OR, Ong J, Dunaway DJ, et al. Enhanced neuro-ophthalmologic evaluation to support separation of craniopagus twins. J Surg Case Rep. 2021;2021:rjaa606 https://doi.org/10.1093/jscr/rjaa606.

22. McLean B. My work experience with Great Ormond Street Hospital Young Persons' Advisory Group for Research. Eye News. 11 June 2021. https://www. eyenews.uk.com/features/ophthalmology/post/my-work-experience-with-greatormond-street-hospital-young-persons-advisory-group-for-research Accessed 15 Nov 2021.

\section{AUTHOR CONTRIBUTIONS}

SRR contributed to the concept and manuscript writing, and is the corresponding author.

\section{FUNDING}

SRR is funded by a National Institute for Health Research (NIHR) Doctoral Fellowship Award ID: NIHR300155. The views expressed are those of the author's and not necessarily those of the National Health Service, NIHR, or the Department of Health and Social Care.

\section{COMPETING INTERESTS}

The author declares no competing interests.

\section{ADDITIONAL INFORMATION}

Correspondence and requests for materials should be addressed to Sohaib R. Rufai.

Reprints and permission information is available at http://www.nature.com/ reprints

Publisher's note Springer Nature remains neutral with regard to jurisdictional claims in published maps and institutional affiliations. 